\title{
Exhaled nitric oxide and sputum eosinophil markers of inflammation in asthmatic children
}

\author{
G.L. Piacentini*, A. Bodini*, S. Costella ${ }^{+}$, L. Vicentini*, P. Mazzi*, S. Sperandio*, A.L. Boner*
}

Exhaled nitric oxide and sputum eosinophil markers of inflammation in asthmatic children. G.L. Piacentini, A. Bodini, S. Costella, L. Vicentini, P. Mazzi, S. Sperandio, A.L. Boner. (C) ERS Journals Ltd 1999 .

ABSTRACT: Exhaled nitric oxide and eosinophil sputum markers are considered noninvasive ways in which to evaluate airway inflammation in asthma. The aim of this study was to evaluate the relationships between these methods of evaluation in asthmatic children.

In a cross-sectional study of 25 mild-moderate asthmatic children (aged 6-13 yrs, 10 patients on inhaled steroids) exhaled NO was measured along with induced sputum by inhalation of hypertonic saline solution. The sputum was processed for eosinophil count and eosinophil cationic protein (ECP) determination. Serum ECP and lung function (forced expiratory volume in one second (FEV1)) were also measured.

A significant correlation was observed between exhaled NO and sputum eosinophils $(\mathrm{r}=0.438, \mathrm{p}=0.032)$ as well as between sputum eosinophils and sputum ECP $(r=0.532$, p $<0.01)$. No correlation was observed among exhaled NO and serum ECP, sputum ECP, FEV1, respectively. Furthermore no correlation was observed between sputum eosinophil (\%) and serum ECP and between sputum eosinophils and FEV1. There was no correlation among the investigated parameters in children treated with inhaled steroids.

In conclusion, exhaled NO and sputum eosinophil counts are concordant in evaluating the degree of airway inflammation in patients with mild-to-moderate asthma. However, the association between these two noninvasive markers becomes less in steroid treated patients.

Eur Respir J 1999; 13: 1386-1390.
*Clinica Pediatrica, Universita' di Verona, Verona, Italy. ${ }^{+}$Istituto Pio XII, Misurina, Belluno, Italy.

Correspondence: A.L. Boner

Clinica Pediatrica

Policlinico Borgo Roma

37134 Verona

Italy

Fax: 39458800993

Keywords: Airway inflammation asthma

eosinophil cationic protein

eosinophils

induced sputum

nitric oxide

Received: October 101998

Accepted after revision February 11999
Airway inflammation is considered a characteristic feature of bronchial asthma and it is not reflected sensitively enough by lung function measurement and symptoms [1]. A number of different markers have therefore been proposed for the evaluation of the magnitude of airway inflammation in asthmatic patients [2].

Several studies support the evidence that the level of exhaled nitric oxide can reflect the degree of airway inflammation in asthmatic patients [3-6] and that it can be reduced by steroid treatment $[7,8]$ and increased by allergen challenge $[4,9]$. Therefore, the levels of exhaled NO have been proposed as a noninvasive method to assess the degree of airway inflammation in asthmatic patients $[3-5,10,11]$, and practical aspects of its applications have been the topic of a recent report by the European Respiratory Society [12].

In the last few years, it has also been shown that it is possible to evaluate the level of bronchial inflammation by examination of sputum induced by inhalation of hypertonic saline $[13,14]$. However, the method of hypertonic saline-induced sputum requires skilled personnel and some laboratory facilities in order to strictly follow the protocol as well as a degree of collaboration by the patients which is difficult to obtain in children.

A recent paper shows that there is a good correlation between exhaled NO and the level of bronchial hyperre- sponsiveness as well as of the number of eosinophils in the sputum of adult asthmatics [2], thus suggesting the potential use of these investigations in the monitoring of asthma severity.

The purpose of the present study was to evaluate the relationship between different noninvasive markers of inflammation, in particular exhaled NO, eosinophils in induced sputum, and serum and sputum eosinophil cationic protein (ECP) levels, in a paediatric population of asthmatics.

\section{Material and methods}

\section{Subjects}

Twenty-five children with mild to moderate asthma, ranging in age 6-13 yrs, were selected among a group of 31 patients evaluated at the residential clinic "Istituto Pio XII" (Misurina, Belluno, Italy), located at $1,756 \mathrm{~m}$ in the Italian Dolomites. The climatic conditions in the area of Misurina are characterized by prolonged periods during which the ground is covered with snow, usually from October to May or June, very low humidity and low temperature. These conditions are unfavourable to the house dust mite. In fact, repeated dust collections from 
mattresses in the residential house detected a mean level of $0.04 \mu \mathrm{g} \cdot \mathrm{g}$ dust $^{-1}$. Furthermore the pollen season is very short during the summer time. The patients recruited in this hospital presented with different degrees of asthma severity, but most of them have mild-to-moderate asthma.

The selection for this study was performed on the basis of the ability of the patients to produce sputum after inhalation of hypertonic saline solution. Six out of the 31 patients were not included in the study because it was not possible to obtain sputum from them. None of the patients presented other active atopic diseases, in particular eczema. None of the patients had respiratory tract infections for at least 1 month before the study. Children could be treated with inhaled steroids and $\beta_{2}$-agonists. The patients treated with inhaled steroids were on regular treatment for at least 2 weeks before the beginning of the study. None of the children participating in the study received oral steroids in the 3 months preceding the study.

The study was approved by the Istituto Pio XII Ethics Committee, and both the children and their parents gave their consent to entering the trial.

\section{Study design}

This cross-sectional study was performed within $48 \mathrm{~h}$ after the children were admitted to the residential house. Blood collections for serum ECP determination were performed within $24 \mathrm{~h}$ of arrival.

The measurement of exhaled NO was performed within the $24 \mathrm{~h}$ prior to the induction of sputum.

\section{NO measurement}

Exhaled NO was measured using a chemiluminescence analyser (Logan LR 2149, Rochester, Kent, UK) [6, 11]. Briefly, the subjects were asked to perform a single slow exhalation through a mouthpiece, against a resistance, and with a biofeedback used to maintain a 5-6 L.min ${ }^{-1}$ steady flow. This method allows the nasopharynx to be separated from the oropharynx by the soft palate, hence preventing the contamination of exhaled NO with nasal NO. This method has been shown to be successfully applicable both in adults and in children. The NO value was measured at the plateau of the end-exhaled reading and expressed in parts per billion ( $\mathrm{ppb}$ ) according to guidelines [12]. Values of NO considered in the data analysis were always measured in the last part of exhalation (plateau exhaled NO), taking the plateau of the end-exhaled $\mathrm{CO}_{2}$ reading as representative of an alveolar sample $[5,6,8,11,12,15]$.

\section{Sputum induction}

Sputum was induced by inhalation of hypertonic saline solution, by a standardized method $[16,17]$, similar to the method originally described by PIN et al. [18]. Briefly, hypertonic saline solution was nebulized using an ultrasonic nebulizer (UN202; Technomedica, Verona, Italy), for four periods of $5 \mathrm{~min}$ each, for a total time of $20 \mathrm{~min}$. The starting concentration was $4 \% \mathrm{NaCl}$ delivered for a total of $10 \mathrm{~min}$, which was followed by a $5 \% \mathrm{NaCl}$ solution for a further $10 \mathrm{~min}$. Before hypertonic saline inhalation, all the patients were premedicated with inhaled salbutamol ( 2 puffs, $200 \mu \mathrm{g}$ ), to inhibit possible bronchoconstriction. The forced expiratory volume in one second (FEV1) was recorded before and $10 \mathrm{~min}$ after salbutamol and then every $5 \mathrm{~min}$ during the saline inhalation. If FEV1 fell by $>20 \%$ of the postbronchodilator value or troublesome symptoms occurred, nebulization was discontinued.

After each period of nebulization, subjects were instructed to rinse their mouth and then to cough sputum into a Petri dish. In the laboratory, the Petri dish was placed against a dark background, making the identification of the sputum portion in the watery saliva easier. Plugs arising from the lower respiratory tract were selected by visual inspection, suspended in dithiotreitrol for $30 \mathrm{~min}$ at $37^{\circ} \mathrm{C}$ and then centrifuged at $400 \times g$ for $10 \mathrm{~min}$ at room temperature. Supernatant was aspirated and frozen at $-70^{\circ} \mathrm{C}$ for later ECP analysis. The cell pellets were washed twice in 1 $\mathrm{mL} 0.9 \%$ saline solution. The pellet was resuspended in $0.9 \%$ saline and the samples were transferred onto slides by cytocentrifugation ( $500 \mathrm{rpm}$ for $5 \mathrm{~min}$ ) with CYTOSPIN 3 (Shandon, Runcorn, UK). Slides were fixed in alcohol $95 \%$ and then stained with May-Grünwald-Giemsa. Slides were coded to be counted blind to the study design. A differential cell count was obtained by counting at least 400 cells. The counts of eosinophils and epithelial cells were expressed as mean percentages of total cells counted by two independent observers, excluding squamous epithelial cells to correct for salivary contamination of the samples.

\section{Serum and sputum eosinophil cationic protein}

ECP was measured by means of Pharmacia CAP System R ECP FEIA (Pharmacia \& Upjohn, Uppsala, Sweden) according to the instructions of the manufacturer. Samples were analysed in duplicate. The inter- and intraassay coefficient of variations were $<8 \%$ and the detection limit was $0.5 \mu \mathrm{g} \cdot \mathrm{L}^{-1}$ (C. Peterson, Pharmacia, Uppsala, Sweden, personal communication, based on the standards of the Pharmacia laboratory where the assays were performed).

Sputum samples were diluted 4 or 20 times in phosphate buffer, $\mathrm{pH} 7.4$, supplemented with $0.15 \mathrm{M} \mathrm{NaCl}, 1 \%$ bovine serum albumin (BSA), $10 \mathrm{mM}$ ethylenediaminetetraacetic acid (EDTA), $0.05 \%$ Tween-20 and $N$-cetyltrimethylammoniumbromide (CTAB). Serum was obtained after allowing venous blood to clot for $60 \mathrm{~min}$ at $20^{\circ} \mathrm{C}$, followed by centrifugation at $4{ }^{\circ} \mathrm{C}$ and $1,600 \times g$.

\section{Statistical analysis}

Data are expressed as mean $\pm \mathrm{SD}$ and as median, lower and upper quartiles (Q1, Q3, respectively). Correlations between the levels of bronchial reactivity and NO measurements at baseline were tested for both groups by Spearman's correlation test.

\section{Results}

Of the 25 children enrolled in the study, 10 were treated with inhaled steroids on a constant basis for at least 2 
weeks, while 15 were receiving only $\beta_{2}$-agonists as needed for at least one month before the time of the study. None of them experienced troublesome symptoms during the test of sputum induction.

Individual data for treatment, FEV1 ( $\%$ of predicted), exhaled NO, eosinophil in the sputum ( $\%$ of total cells), serum and sputum ECP and respective median (Q1, Q3) values are reported in table 1.

Considering all the patients, significant correlations were found between exhaled NO and sputum eosinophils (\%) $(\mathrm{r}=0.438, \mathrm{p}=0.032)$ (fig. 1) and between sputum ECP and sputum eosinophils $(\%)(\mathrm{r}=0.532, \mathrm{p}<0.01)$ (fig. 2$)$. No significant correlation was found among exhaled NO and serum ECP, sputum ECP, FEV1, respectively. Similarly, no correlation was found between sputum eosinophil (\%) and serum ECP or between sputum eosinophils (\%) and FEV1.

Table 2 shows the median values for the investigated parameters considering the children receiving or not receiving inhaled steroids (table 1). The group treated with inhaled steroids showed slightly lower levels of exhaled $\mathrm{NO}$, sputum ECP and sputum eosinophils, as compared to the group not receiving steroid therapy (NS).

In the group of the children treated with steroids there was no significant correlation among the investigated parameters.

In the group of 15 children not receiving steroid treatment there were significant correlations between exhaled NO and sputum eosinophils (\%) $(r=0.532, \mathrm{p}<0.05)$ (fig. 1), as well as between sputum ECP and sputum eosinophils $(\%)(r=0.694, p<0.05)$, confirming the results observed in the entire group.

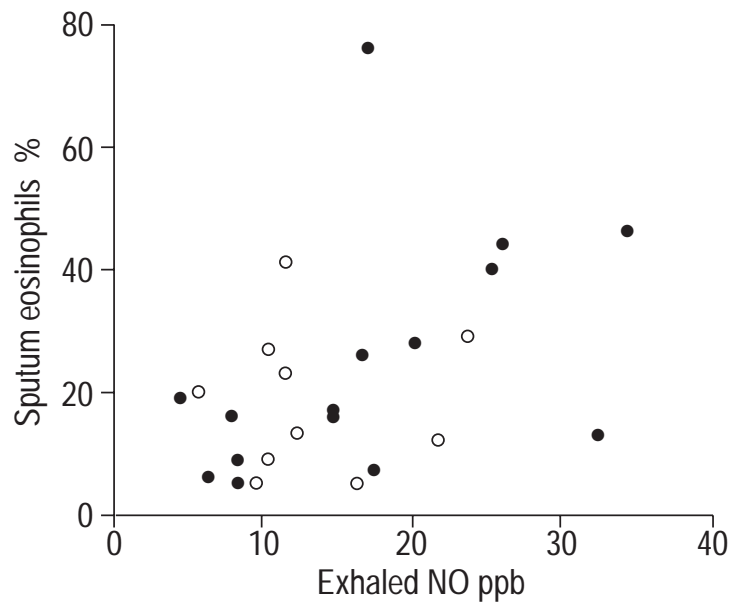

Fig. 1. - Relationship between exhaled nitric oxide and sputum eosinophils $(\%)$ in the total group $(\mathrm{r}=0.438, \mathrm{p}=0.032)$. $\bigcirc$ : steroid-treated; steroid-untreated $(\mathrm{r}=0.532, \mathrm{p}<0.05)$. ppb: parts per billion.

\section{Discussion}

The present findings of a significant correlation between exhaled NO and sputum eosinophils are in agreement with previous observations in asthmatic adults. KANAZAWA et al. [19] showed a relationship between eosinophil count in the sputum and NO derivatives in asthmatic patients. Similarly, JATAKANON et al. [1] showed a correlation between eosinophil percentage in the sputum and exhaled NO in asthmatic adults. Therefore the present data support and further extend the usefulness of measuring

Table 1. - Individual data for treatment and investigated parameters

\begin{tabular}{|c|c|c|c|c|c|c|}
\hline $\begin{array}{l}\text { Patient } \\
\text { No. }\end{array}$ & Treatment* & $\begin{array}{l}\text { FEV1 } \\
\% \text { pred }\end{array}$ & $\begin{array}{c}\text { Exhaled NO } \\
\text { ppb }\end{array}$ & $\begin{array}{c}\text { Serum ECP } \\
\mu \mathrm{g} \cdot \mathrm{L}^{-1}\end{array}$ & $\begin{array}{c}\text { Sputum } \\
\text { eosinophil \% }\end{array}$ & $\begin{array}{c}\text { Sputum ECP } \\
\mu \mathrm{g} \cdot \mathrm{L}^{-1}\end{array}$ \\
\hline 1 & IS & 97 & 11.5 & 13.2 & 37 & 411.8 \\
\hline 2 & - & 98 & 16.7 & & 22 & 84.6 \\
\hline 3 & IS & 113 & 12.3 & 20.1 & 9 & 8.6 \\
\hline 4 & - & 94 & 17.1 & & 72 & 172 \\
\hline 5 & IS & 103 & 16.3 & & 1 & 17.7 \\
\hline 6 & IS & 107 & 9.5 & & 1 & 68.8 \\
\hline 7 & IS & 98 & 11.5 & 9.8 & 19 & 30.3 \\
\hline 8 & - & 114 & 20.2 & 24.8 & 24 & 119 \\
\hline 9 & IS & 125 & 23.8 & & 25 & 115.1 \\
\hline 10 & - & 112 & 26.2 & 19 & 40 & 50.4 \\
\hline 11 & IS & 113 & 5.6 & 4.3 & 16 & 44.9 \\
\hline 12 & - & 108 & 8.3 & & 1 & 57.2 \\
\hline 13 & IS & 74 & 10.3 & & 5 & 65.6 \\
\hline 14 & - & 141 & 17.5 & 9.3 & 3 & 42.1 \\
\hline 15 & - & 128 & 4.4 & 20.3 & 15 & 110.6 \\
\hline 16 & - & 116 & 7.9 & 5 & 12 & 237 \\
\hline 17 & - & 62 & 25.4 & & 36 & 234.8 \\
\hline 18 & - & 136 & 8.3 & 6.4 & 5 & 71.7 \\
\hline 19 & - & 118 & 14.7 & 9.6 & 12 & 112.2 \\
\hline 20 & - & 79 & 34.5 & 12.5 & 42 & 184.9 \\
\hline 21 & IS & 99 & 10.3 & & 23 & 26.8 \\
\hline 22 & - & 99 & 32.5 & 12.9 & 9 & 8 \\
\hline 23 & - & 81 & 6.3 & 2.8 & 2 & 10 \\
\hline 24 & - & 88 & 14.7 & & 13 & 199.5 \\
\hline 25 & IS & 88 & 21.8 & 12.6 & 8 & 29.4 \\
\hline Median & & 103 & 14.7 & 12.5 & 13 & 68.8 \\
\hline Q1-Q3 & & $92.5-114.5$ & $9.2-20.6$ & $7.12-17.55$ & $5-24.2$ & $30.07-132.25$ \\
\hline
\end{tabular}

FEV1: forced expiratory volume in the second; ppb: parts per billion; ECP: eosinophil cationic protein; IS: inhaled steroids. Q1-Q3: lower and upper quartiles, respectively. ${ }^{*}: \beta_{2}$-agonists were allowed as needed for all subjects. 


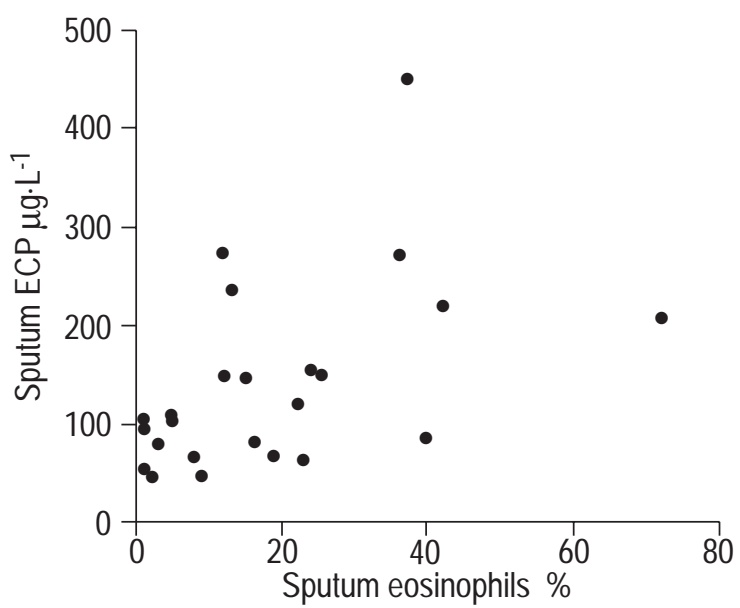

Fig. 2. - Relationship between sputum eosinophil cationic protein (ECP) and sputum eosinophils $(\%)(\mathrm{r}=0.532, \mathrm{p}<0.01)$. (Two subjects overlap in the graph, being sputum eosinophil $9 \%$ in both cases and sputum ECP 8 and $8.6 \mu \mathrm{g} \cdot \mathrm{L}^{-1}$ respectively.)

exhaled NO for the evaluation of airway inflammation in asthmatic children, who may particularly benefit from the use of a noninvasive method of assessment.

Inhaled steroids have been demonstrated to be effective in decreasing exhaled NO in asthmatic patients [7, 8], and effectively, despite a failure to show statistically significant differences, the present steroid-treated patients tended to have lower exhaled NO, sputum eosinophils and sputum ECP compared to the steroid-untreated group, but not for serum ECP. The data of the single patients in the steroid-treated group (table 1) suggest the persistence of a certain degree of airway inflammation in this group, since levels of exhaled NO $>10 \mathrm{ppb}$ were observed in eight out of 10 and sputum eosinophil percentage $\geq 5$ in nine out of 10 of this group. Therefore, it is possible that the lack of a statistically significant relationship between exhaled NO and sputum eosinophil percentage in the steroid-treated children may be due to a type 2 error rather than to a direct effect of the treatment, although this cannot be excluded. Nevertheless, a parallelism in the reduction of NO production and airway inflammation is proposed in a recent hypothesis by BARNES and LIEw [20] which suggests that inhaled steroids can inhibit eosinophil inflammation of asthma by the inhibition of inducible nitric oxide synthase (iNOS).

The relationship between exhaled $\mathrm{NO}$ and sputum eosinophils could be explained with a causal link in the development and maintenance of airway inflammation in asthma. In fact, as suggested by BARNES and LIEW [20],

Table 2. - Median and lower and upper quartile values for the investigated parameters considering the children receiving or not receiving inhaled steroids

\begin{tabular}{lcc}
\hline & Steroid-untreated & Steroid-treated \\
\hline FEV1 \% pred & $108(89.5-117.5)$ & $101(97-113)$ \\
Exhaled NO ppb & $16.7(8.3-24.1)$ & $11.5(10.3-16.3)$ \\
Sputum eosinophil \% & $13.0(6-33)$ & $12.5(5-23)$ \\
Sputum ECP $\mu \mathrm{g} \cdot \mathrm{L}^{-1}$ & $110.6(52.1-181.6)$ & $37.6(26.8-68.8)$ \\
Serum ECP $\mu \mathrm{g} \cdot \mathrm{L}^{-1}$ & $11.0(6.4-19)$ & $12.6(8.4-14.9)$ \\
\hline
\end{tabular}

FEV1: forced expiratory volume in one second; ppb: parts per billion; ECP: eosinophil cationic protein. increased levels of NO from the airways could concur in eosinophil recruitment in the airway by the activation of T-helper (Th) 2 cells and the consequent release of interleukin (IL)-5.

In this study no correlation between serum ECP and the other investigated parameters of inflammation was found. A previous study has suggested that serum ECP reflects the degree of eosinophilic inflammation in the airways and the disease activity in asthma [21]. Three studies examining the correlations between serum and sputum ECP levels showed contrasting results, since CLAMAN et al. [22] found a positive correlation, whereas VIRCHOw et al. [23], and, more recently, Pizzichini et al. [24] failed to find such correlations. This could be influenced by the duration and level of antigen exposure. It is possible that low and/or intermittent allergen exposure may preferentially activate eosinophils in the airway, whereas a more consistent and/ or longer allergen exposure may have a systemic effect. Furthermore, it is also possible that different patients may present different patterns of local or systemic inflammatory response. In a previous study by the authors [17], a significant reduction in serum ECP and eosinophil protein $X(E P X)$ levels were observed after a prolonged period of antigen avoidance in a group of house dust mite allergic asthmatic children, which suggested a reduction in eosinophil activation. In that study, however, there was no direct parameter of evaluation of airway inflammation and the changes in serum eosinophil markers of activation were not concordant with the changes in the bronchial responsiveness to methacholine. In agreement with VIRCHOw et al. [23] and Pizzichini et al. [24], the results of the present study suggest that airway parameters, such as exhaled NO, sputum eosinophil contents and sputum ECP levels, may better represent the actual degree of airway inflammation than serum ECP. Therefore, serum ECP may possibly be seen as a general marker of eosinophil activation rather than a specific marker for pulmonary disease. In this study, sputum ECP also failed to correlate with exhaled NO and sputum ECP. Despite these results being consistent with those obtained in adults by JATAKANON et al. [1], it is difficult to explain the correlation of NO to sputum eosinophils, but not sputum ECP. It cannot be excluded that these results could potentially be influenced by errors occurring during sample collection, handling and analysis.

In contrast to previous finding [23, 25-27], but in agreement with the recent paper by JATAKANON et al. [1], no correlation between exhaled NO and FEV1 could be shown. This could be due to the relatively stable clinical conditions and satisfactory lung function levels of the patients in the present study. However, it cannot be excluded that this discrepancy could reflect the expression of different aspects of the asthmatic disease. Therefore, these data may suggest to complement clinical and spirometric measurements with the evaluation of the degree of airway inflammation by means of tests such as the measurement of exhaled NO and sputum eosinophil number to monitor asthma severity.

In conclusion, the results of the study by JATAKANON et al. [1] have been confirmed and have been extended to a paediatric population with the finding that exhaled NO and sputum eosinophil counts are concordant in evaluating the degree of airway inflammation in asthma, particularly in children not receiving inhaled steroid 
treatment. In the total group the correlations are weaker probably because of the fact that the markers in the steroid group are not correlated. In addition no relationship between local airway (exhaled NO, sputum eosinophil count and eosinophil cationic protein) and serum (eosinophil cationic protein) markers of inflammation were observed. Furthermore, it was observed that, in spite of normal lung function, a residual degree of inflammation can still be persistent despite treatment with inhaled steroids and in mild patients receiving only bronchodilators when needed. Exhaled NO and sputum eosinophil counts may represent sensitive markers of minimal persistent inflammation.

\footnotetext{
Acknowledgements. The authors are grateful to C. Peterson, Pharmacia \& Upjohn, Uppsala, Sweden, for performing ECP assays.
}

\section{References}

1. Jatakanon A, Lim S, Kharitonow SA, Chung KF, Barnes PJ. Correlation between exhaled nitric oxide, sputum eosinophils, and methacholine responsiveness in patients with mild asthma. Thorax 1998; 53: 91-95.

2. Holgate ST. Biomarkers of asthma. Lancet 1998; 351: 1300-1301.

3. Alving K, Weitzberg E, Lundberg JM. Increased amount of nitric oxide in exhaled air of asthmatics. Eur Respir $J$ 1993; 6: 1368-1370.

4. Kharitonov SA, Yates DH, Robbins RA, Logan-Sinclair $\mathrm{R}$, Shinebourne EA, Barnes PJ. Increased nitric oxide in exhaled air of asthmatic patients. Lancet 1994; 343: 133135.

5. Kharitonov SA, Barnes PJ. Exhaled nitric oxide: a marker of airway inflammation? Curr Opin Anaesthesiol 1996; 9: $542-548$.

6. Kharitonov SA, Fan Chung K, Evans D, O'Connor BJ, Barnes PJ. Increased exhaled nitric oxide in asthma is mainly derived from the lower respiratory tract. $\mathrm{Am} \mathrm{J}$ Respir Crit Care Med 1996; 153: 1773-1780.

7. Kharitonov SA, Yates DH, Barnes PJ. Inhaled glucocorticoids decrease nitric oxide in exhaled air of asthmatic patients. Am J Respir Crit Care Med 1996; 153: 454-457.

8. Kharitonov SA, Yates DH, Chung KF, Barnes PJ. Changes in the dose of inhaled steroid affect exhaled nitric oxide levels in asthmatic patients. Eur Respir $J$ 1996; 9: 196-201.

9. Deykin A, Halpeern O, Massaro AF, Drazen JM, Israel E. Expired nitric oxide after bronchoprovocation and repeated spirometry in patients with asthma. Am J Respir Crit Care Med 1998; 157: 769-775.

10. Barnes PJ, Kharitonov SA. Exhaled nitric oxide: a new lung function test. Thorax 1996; 51: 233-237.

11. Lundberg JON, Weitzberg E, Lundberg JM, Alving K
Nitric oxide in exhaled air. Eur Respir $J$ 1996; 9: 26712680.

12. Kharitonov SA, Alving K, Barnes PJ. Exhaled and nasal nitric oxide measurements: recommendations. Eur Respir J 1997; 10: 1683-1693.

13. Pavord ID, Pizzichini MMM, Pizzichini E, Hargreave FE. The use of induced sputum to investigate airway inflammation. Thorax 1997; 52: 498-501.

14. Spanevello A, Migliori GB, Sharara A, et al. Induced sputum to assess airway inflammation: a study of reproducibility. Clin Exp Allergy 1997; 27: 1138-1144.

15. Byrnes CA, Dinarevic S, Shinebourne EA, Barnes PJ, Bush A. Exhaled nitric oxide measurements in normal and asthmatic children. Pediatric Pulmonol 1997; 24: 312-318.

16. Piacentini GL, Vicentini L, Mazzi P, Chilosi M, Martinati L, Boner AL. Mite-antigen avoidance can reduce bronchial epithelial shedding in allergic asthmatic children. Clin Exp Allergy 1998; 28: 561-567.

17. Piacentini GL, Martinati L, Fornari A, et al. Antigen avoidance in a mountain environment: influence on basophil releasability in children with allergic asthma. $J$ Allergy Clin Immunol 1993; 92: 644-650.

18. Pin I, Gibson PG, Kolendowicz R, et al. Use of induction sputum cell counts to investigate airway inflammation in asthma. Thorax 1992; 47: 25-29.

19. Kanazawa H, Shoji S, Yamada M, et al. Increased levels of nitric oxide derivatives in induced sputum in patients with asthma. J Allergy Clin Immunol 1997; 99: 624-629.

20. Barnes PJ, Liew FY. Nitric oxide and asthmatic inflammation. Immunol Today 1995; 9: 416S.

21. Niimi A, Amitani R, Suzuki K, Tanaka T, Murayama T, Kuze F. Serum eosinophil cationic protein as a marker of eosinophilic inflammation in asthma. Clin Exp Allergy 1997; 28: 233-240.

22. Claman DM, Boushey HA, Liu J, Wong H, Fahy JV. Analysis of induced sputum to examine the effect of prednisone on airway inflammation in asthmatic subjects. J Allergy Clin Immunol 1994; 94: 861-869.

23. Virchow J-C Jr, Hölscher U, Virchow C Sr. Sputum ECP levels correlate with parameters of airflow obstruction. Am Rev Respir Dis 1992; 146: 604-606.

24. Pizzichini E, Pizzichini MMM, Efthimiadis A, Dolovich $\mathrm{J}$, Hargreave FE. Measuring airway inflammation in asthma: eosinophils and eosinophilic cationic protein in induced sputum compared with peripheral blood. $J$ Allergy Clin Immunol 1997; 99: 539-544.

25. Bailgelman W, Chondons S, Pizzuto D, Cupples LA. Sputum and blood eosinophils during corticosteroid treatment of acute exacerbations of asthma. Am J Med 1983; 75: 929-936.

26. Alfaro C, Sharma OP, Navarro L, Glovsky MM. Inverse correlation of expiratory lung flows and sputum eosinophils in status asthmaticus. Ann Allergy 1989; 63: 251254.

27. Artlinch A, Hagenah JU, Jonsas S, Ahrens P, Gortner L. Exhaled nitric oxide in childhood asthma. Eur $J$ Pediatr 1996; 155: 698-701. 